\title{
Hemodynamic Effects of Synephrine Treatment in Portal Hypertensive Rats
}

\author{
Yi-Tsau Huang ${ }^{1}$, Han-Chieh Lin ${ }^{2} *$, Yuan-Yi Chang ${ }^{1}$, Ying-Ying Yang ${ }^{2}$, Shou-Dong Lee ${ }^{2}$ and Chuang-Ye Hong ${ }^{1}$ \\ ${ }^{1}$ Institute of Traditional Medicine, National Yang-Ming University, Taipei, Taiwan \\ ${ }^{2}$ Division of Gastroenterology, Department of Medicine, Taipei Veterans General Hospital, \\ and School of Medicine, National Yang-Ming University; 201, Section 2, Shih-Pai Road, Taipei 11217, Taiwan
}

Received September 11, 2000 Accepted November 22, 2000

\begin{abstract}
Synephrine, a sympathomimetic $\alpha_{1}$-adrenoceptor agonist, has been shown to induce dosedependent portal hypotensive effects after acute intravenous infusion. The present study was undertaken to investigate the hemodynamic effects of 8-day administration of synephrine in portal hypertensive rats. Portal hypertension was induced by either partial portal vein ligation (PVL) or bile duct ligation (BDL). Portal hypertensive rats were allocated into one of two groups: vehicle group $(0.1 \mathrm{~N} \mathrm{HCl}, 0.5 \mathrm{ml} / 12 \mathrm{~h})$ or synephrine group $(1 \mathrm{mg} / \mathrm{kg}$ per $12 \mathrm{~h})$, with $7 \mathrm{rats}$ in each group. Synephrine or vehicle was administered by gavage into PVL and BDL rats for 8 consecutive days. Systemic as well as splanchnic hemodynamic parameters were measured thereafter. Synephrine significantly ameliorated the hyperdynamic state in both PVL and BDL rats. The portal venous pressure in PVL and BDL rats $(-13.5 \%$ and $-10.1 \%$, respectively), portal tributary blood flow $(-19.5 \%$ and $-20.4 \%)$ and cardiac index $(-12.1 \%$ and $-18.8 \%)$ were significantly reduced, while mean arterial pressure (10.4\% and $23.4 \%)$ and systemic $(26.3 \%$ and $51.0 \%)$ as well as portal territory $(47.1 \%$ and $67.7 \%)$ vascular resistance were enhanced by treatment of synephrine as compared with vehicle treatment. Our results showed that eight-day administration of synephrine exerted beneficial hemodynamic effects in two models of portal hypertensive rats.
\end{abstract}

Keywords: Portal hypertension, Hemodynamics, Synephrine, Radioactive microsphere method

The hyperdynamic circulation of portal hypertension is characterized by decrease in arterial blood pressure and vascular resistance and increase in portal venous pressure (PVP) and splanchnic blood flow (1). It has been reported that the portal pressure gradient is an important risk factor for esophageal variceal hemorrhage, a major complication of portal hypertension $(2,3)$. The pharmacological treatment of portal hypertension aims to treat acute bleeding episodes or prevent variceal bleeding $(2,3)$. There are mainly two types of drugs to reduce portal hypertension, either by reducing portal tributory blood flow (PTBF) (e.g., terlipressin [triglycyl-lysine-vasopressin, a synthetic vasopressin analogue with long-lasting effects], octreotide [a synthetic 8-amino-acid analogue of somatostatin with prolonged action], and propranolol) or by reducing intrahepatic and porto-systemic collateral vascular resistances (e.g., nitrovasodilators) $(1-3)$. Current therapeutic drugs for portal hypertension are quite limited due to their side

*Corresponding author. FAX: +886-2-2873 9318

E-mail: hclin@vghtpe.gov.tw effects or low efficacy. Terlipressin and somatostatin (an inhibitor of gut-derived secretion of vasodilatory peptides such as glucagon, vasoactive intestinal peptide, etc.) are two widely used vasoconstrictors in the treatment of acute variceal bleeding, while propranolol is used as a prophylactic drug for prevention of variceal rebleeding $(2,3)$. However, side effects of severe systemic vasoconstriction and cardiodepresssion are still a significant clinical concern for use of terlipressin (4), while about one third of cirrhotic patients are non-responders to propranolol $(2,3)$. A recent clinical study also indicated that propranolol could not prevent the development of large esophageal varices in cirrhotic patients after 2-year treatment (5). In the context of making efforts to find some potential alternatives from the Chinese materia medica, we have reported previously that acute intravenous administration of the aqueous extract of Citrus aurantium $\mathrm{L}$ or its active principle synephrine dose dependently reduced portal pressure and increased arterial pressure in portal vein stenosed rats, suggesting similar mechanisms of action to those induced by such vasoconstrictors as vasopressin (6). Synephrine (1-[4-hy- 
droxyphenyl]-2-methyl-aminoethanol, $\mathrm{C}_{9} \mathrm{H}_{13} \mathrm{NO}_{2}$, molecular weight, 167.2), a sympathomimetic compound with $\alpha$ adrenoceptor-mediated vasoconstrictive activity (6), is one of the active principles in Citrus aurantium, and it has been shown to increase systemic arterial pressure after intravenous infusion into humans as well as animals $(7-9)$. The current study was undertaken to evaluate the hemodynamic effects of chronic administration of synephrine on two models of portal hypertension in rats.

\section{MATERIALS AND METHODS}

\section{Study protocols}

Hemodynamic effects of synephrine treatment were evaluated in two models of portal hypertensive rats, i.e., PVL rats (partial portal vein ligation, without cirrhosis) and BDL rats (bile duct ligation, with cirrhosis). Each PVL or BDL rat received only one of the two regimens: synephrine $(1 \mathrm{mg} / \mathrm{kg}$ per $12 \mathrm{~h})$ or vehicle $(0.1 \mathrm{~N} \mathrm{HCl}, 0.5 \mathrm{ml} / 12 \mathrm{~h})$. The dose for synephrine $(1 \mathrm{mg} / \mathrm{kg}$ per $12 \mathrm{~h}$ ) was chosen according to results of our pilot study showing that this dose was effective and higher doses of synephrine did not induce better hemodynamic benefits. For example, PVL rats receiving synephrine at 1 and $10 \mathrm{mg} / \mathrm{kg}$ per $12 \mathrm{~h}$ for 8 days had PVP at $11.5 \pm 0.4$ and $10.6 \pm 0.4 \mathrm{mmHg}$, respectively, as compared with rats receiving vehicle, PVP at $13.3 \pm 0.5 \mathrm{mmHg}$. PTBF in PVL rats receiving synephrine at 1 and $10 \mathrm{mg} / \mathrm{kg}$ per $12 \mathrm{~h}$ was $4.04 \pm 0.32$ and $3.61 \pm$ $0.10 \mathrm{ml} / \mathrm{min}$ per $100 \mathrm{~g}$ body weight, respectively, as compared with rats receiving vehicle, PTBF at $5.02 \pm 0.19 \mathrm{ml}$ $/ \mathrm{min}$ per $100 \mathrm{~g}$ body weight. The values of either PVP or PTBF were not significantly different between PVL rats receiving synephrine at 1 and $10 \mathrm{mg} / \mathrm{kg}$ per $12 \mathrm{~h}$. Synephrine or vehicle was administered by gavage into PVL and BDL rats for 8 consecutive days, starting just after partial portal vein ligation and three weeks after bile duct ligation, respectively. Two separate groups of sham-operated (Sham) rats were included for hemodynamic comparison with PVL and BDL rats. There were 7 rats allocated to each regimen or group, with a total of 42 rats studied. Systemic as well as splanchnic hemodynamic parameters were measured thereafter. Animal studies were approved by the Animal Experiment Committee of the National Yang-Ming University, and they were conducted humanely, in accordance with Guide for the Care and Use of Laboratory Animals [National Academic Press, USA, 1996].

\section{PVL rats}

Portal hypertension without cirrhosis was induced by partial portal vein ligation, according to the method of Chojkier and Groszmann (10) and as previously reported (11). Briefly, male Sprague-Dawley rats $(220-260 \mathrm{~g})$ were anesthetized with ether. A midline incision was made, and the portal vein proximal to the bifurcation was exposed. A 3-0 silk ligature was made around the portal vein and a piece of PE 50 tubing (Clay Adams, Parsippany, NJ, USA). The PE tubing was then removed and the abdomen closed.

\section{BDL rats}

Portal hypertension with cirrhosis was induced by bile duct ligation, according to the method of Kountouras et al. (12) and as previously reported (13). Briefly, male Sprague-Dawley rats $(230-280 \mathrm{~g})$ were anesthetized with ether. A midline incision was made, and double ligation of the bile duct was performed by a proximal ligature around the bile duct in the hilus of the liver and by a distal ligature close to its entry into the duodenum. A cut was then made between ligatures. The abdomen was closed and injections of vitamin $\mathrm{K}_{1}$ (50 $\mu \mathrm{g}$ once per week) and cefmetazole (10 mg, single dose) were given intramuscularly to improve survival.

\section{Sham rats}

In Sham rats, the portal vein and bile duct was mobilized but not ligated under ether anesthesia and the abdomen was closed.

\section{Hemodynamic measurement}

On the ninth day after synephrine or vehicle treatment, the rats were anesthetized with ketamine $(100 \mathrm{mg} / \mathrm{kg})$ after an overnight fast. A tracheostomy was performed to keep the airway patent. The ileocolic vein was cannulated with PE 50 tubing for measuring PVP and the femoral artery for arterial blood pressure. Another catheter, made of PE 50 tube connected to a PE-10 tip, was inserted into the left ventricle through the right carotid artery for radiomicrosphere injection (see below). Correct positioning of the catheter was verified by blood pressure tracing. All catheters were fixed with cyanoacrylate glue applied over puncture sites. Changes in pressures and heart rate were monitored by a polygraph (RS 3400; Gould, Valley View, OH, USA) via strain-gauge transducers (P23XL; Viggo-Spectramed, Oxnard, CA, USA). A steady baseline was recorded for $30 \mathrm{~min}$. After pressure measurement, cardiac output (CO) and regional organ blood flows were measured using the radioactive microsphere technique with reference sample method as previously described (14). In brief, the reference sample was withdrawn from the femoral artery into a syringe for $75 \mathrm{~s}$ at a rate of $0.8 \mathrm{ml} / \mathrm{min}$, using a Harvard pump (Harvard Apparatus, Millis, MA, USA). Ten seconds after withdrawal of the reference sample, approximately $60,000{ }^{57} \mathrm{Co}$-labeled microspheres of $15-\mu \mathrm{m}$ diameter were injected into the left ventricle over a period of 25 to $30 \mathrm{~s}$. The catheter was then flushed with $0.5 \mathrm{ml} 0.9 \%$ saline. Animals were then killed with a bolus dose of saturated $\mathrm{KCl}$, and individual organs were dissected. The radioactiv- 
ity of each organ and the reference blood sample was counted in a $\gamma$-scintillation counter (Auto Gamma 5000; Packard, Downers Grove, IL, USA). Adequate mixing of microspheres was assumed when the difference of radioactivity between the left and right kidneys was below $10 \%$.

$\mathrm{CO}$ was calculated by the following formula: $\mathrm{CO}(\mathrm{ml}$ $/ \mathrm{min})=[$ radioactivity injected $(\mathrm{cpm}) /$ reference sample radioactivity $(\mathrm{cpm})] \times 0.8(\mathrm{ml} / \mathrm{min})$. Cardiac index $(\mathrm{CI})$ was derived from the following formula: CI $(\mathrm{ml} / \mathrm{min}$ per $100 \mathrm{~g}$ body weight $)=\mathrm{CO} / 100 \mathrm{~g}$ body weight. Regional organ blood flows were calculated according to the following formula: organ blood flow $=[$ organ radioactivity $(\mathrm{cpm})$ $/$ radioactivity injected $(\mathrm{cpm})] \times \mathrm{CI}$. Organ blood flow was expressed as $\mathrm{ml} / \mathrm{min}$ per $100 \mathrm{~g}$ body weight. PTBF (expressed as $\mathrm{ml} / \mathrm{min}$ per $100 \mathrm{~g}$ body weight) was taken as the sum of blood flows of the spleen, stomach, small intestine, colon, and mesentery with pancreas. Systemic vascular resistance (SVR) was calculated as mean arterial pressure $(\mathrm{MAP}[\mathrm{mmHg}]) \times 80 / \mathrm{CI}$. Portal tributary vascular resistance $(\mathrm{PTVR})=[\mathrm{MAP}-\mathrm{PVP}(\mathrm{mmHg})] \times 80 /$ PTBF. Hepato-collateral vascular resistance (HCVR) $=\mathrm{PVP} \times 80 / \mathrm{PTBF}$. Renal vascular resistance $(\mathrm{RVR})$ was calculated as MAP / renal blood flow. Vascular resistances were expressed as $\mathrm{dyn} \cdot \mathrm{s} \cdot \mathrm{cm}^{-5} \cdot 10^{3} / 100 \mathrm{~g}$ body weight $\left(1\right.$ dyn $\left.=10^{-5} \mathrm{~N}\right)$.

\section{Drugs}

$( \pm)$-Synephrine (>99\%) was purchased from Sigma Chemical Co. (St. Louis, MO, USA) and dissolved in $0.1 \mathrm{~N}$ $\mathrm{HCl}$ as a stock solution of $1 \mathrm{mg} / \mathrm{ml}$. The synephrine solution was stored at $4^{\circ} \mathrm{C}$ in the refrigerator and used within 7 days after preparation. Ketamine was from Parke-Davis Co. (Chunli, Taiwan). ${ }^{57}$ Co microspheres were purchased from Du Pont Medical Products (North Billerica, MA, USA) and prepared by suspending $100 \mu 1$ stock in $1.5 \mathrm{ml}$ Tween $80(0.05 \%)$. Vigorous mixing was always performed before taking a small aliquot for radioactivity counting as well as for injection.

\section{Statistics}

Data are expressed as means \pm S.E.M. One way analysis of variance with Scheffe's correction for multiple comparison was used for statistical analysis. Significance was determined at $P<0.05$.

\section{RESULTS}

The hemodynamic effects of synephrine or vehicle treatment in PVL rats are shown in Table 1. A typical portal hypertensive state and hyperdynamic circulation was manifested in PVL rats receiving vehicle, including higher CI, PVP, PTBF and hepatic arterial blood flows (HABF), and lower MAP, PTVR and SVR, as compared to Sham rats $(15,16)$. Eight-day treatment of synephrine partially corrected the hyperdynamic state of PVL rats in terms of increasing MAP, SVR and PTVR, and decreasing PVP, CI and PTBF. Both systemic and splanchnic hemodynamics were improved, but not completely corrected, in synephrine-treated PVL rats, as they still exhibited hyperdynamic abnormalities as compared with Sham rats (Table 1).

The hemodynamic effects of synephrine or vehicle treatment in BDL rats are shown in Table 2. A typical portal hypertensive state and hyperdynamic circulation was manifested in BDL rats receiving vehicle, including higher $\mathrm{CI}$, PVP, PTBF, HABF as well as HCVR, and lower MAP, PTVR and SVR, as compared to Sham rats $(16,17)$. Eightday treatment of synephrine partially corrected the hyperdynamic state of BDL rats in terms of increasing MAP, SVR and PTVR, and decreasing PVP, CI and PTBF. Both systemic and splanchnic hemodynamics were improved, but not completely corrected, in synephrine-treated BDL rats, as they still exhibited hyperdynamic abnormalities as compared with Sham rats (Table 2).

There was no difference in the body weights between those receiving synephrine or vehicle administration in PVL rats $(249 \pm 7$ vs $245 \pm 9 \mathrm{~g})$ or BDL rats $(329 \pm 13$ vs $329 \pm 9 \mathrm{~g})$. Eight-day synephrine or vehicle administration induced no death or notable gross change in PVL or BDL rats.

\section{DISCUSSION}

The results of our present study showed that 8-day administration of synephrine at $1 \mathrm{mg} / \mathrm{kg}$ per $12 \mathrm{~h}$ significantly ameliorated, but not completely corrected, the portal hypertensive and splanchnic hyperemic state in both PVL and BDL rats. Although the reduction of PVP by synephrine was moderate $(10-13.5 \%$ in PVL and BDL rats as compared with vehicle treatment), the common characteristics of the portal hypertensive and hyperdynamic state, including decrease in systemic arterial pressure and vascular resistance as well as increase in PVP, splanchnic blood flow and CI were all improved. The degree of reduction by synephrine in PVP and PTBF (-19.5\% and $-20.4 \%)$ was similar in PVL and BDL rats, while the degree of enhancement in MAR (10.4\% and 23.4\%), SVR (26.3\% and 51.0\%) and PTVR (47.1\% and 67.7\%) tended to be less in PVL rats than in BDL rats. It has been reported that repeated administration of portal hypotensive drugs such as propranolol $(18-20)$, octreotide $(14,20,21)$, organic nitrates (22), prazosin (23), clonidine (24), verapamil $(25,26)$, tetrandrine (27) or tetramethylpyrazine (28) into cirrhotic or portal hypertensive animals also leads to amelioration of portal hypertension or splanchnic hyperemia. However, administration of "vasodilating" portal hypotensive drugs such as organic nitrates (22), prazosin (23), verapamil (26), 
Table 1. Hemodynamic values in sham-operated rats and partial-portal-vein-ligated rats receiving vehicle or synephrine (1 mg $/ \mathrm{kg}$ per $12 \mathrm{~h}$ ) for 8 days

\begin{tabular}{lccc}
\hline & Sham rats & PVL-vehicle rats & PVL-synephrine rats \\
\hline Number of rats & 7 & 7 & 7 \\
CI (ml/min per $100 \mathrm{~g})$ & $28.9 \pm 0.6$ & $43.0 \pm 1.1^{\mathrm{a}}$ & $37.8 \pm 0.9^{\mathrm{ab}}$ \\
MAP $(\mathrm{mmHg})$ & $122 \pm 5$ & $96 \pm 2^{\mathrm{a}}$ & $106 \pm 1^{\mathrm{ab}}$ \\
Heart rate $(\mathrm{bpm})$ & $339 \pm 8$ & $321 \pm 4$ & $330 \pm 7$ \\
SVR $\left(\right.$ dyn $\left.\cdot \mathrm{s} \cdot \mathrm{cm}^{-5} \times 10^{3} / 100 \mathrm{~g}\right)$ & $338 \pm 12$ & $179 \pm 6^{\mathrm{a}}$ & $226 \pm 6^{\mathrm{ab}}$ \\
PVP $(\mathrm{mmHg})$ & $6.9 \pm 0.3$ & $13.3 \pm 0.5^{\mathrm{a}}$ & $11.5 \pm 0.4^{\mathrm{ab}}$ \\
PTBF $(\mathrm{ml} / \mathrm{min}$ per $100 \mathrm{~g})$ & $3.17 \pm 0.24$ & $5.02 \pm 0.19^{\mathrm{a}}$ & $4.04 \pm 0.32^{\mathrm{ab}}$ \\
PTVR $\left(\mathrm{dyn} \cdot \mathrm{s} \cdot \mathrm{cm}^{-5} \times 10^{3} / 100 \mathrm{~g}\right)$ & $3014 \pm 277$ & $1325 \pm 69^{\mathrm{a}}$ & $1949 \pm 155^{\mathrm{ab}}$ \\
HCVR $\left(\mathrm{dyn} \cdot \mathrm{s} \cdot \mathrm{cm}^{-5} \times 10^{3} / 100 \mathrm{~g}\right)$ & $182 \pm 20$ & $213 \pm 11$ & $235 \pm 19$ \\
HABF $(\mathrm{ml} / \mathrm{min}$ per $100 \mathrm{~g})$ & $0.47 \pm 0.07$ & $0.99 \pm 0.12^{\mathrm{a}}$ & $0.75 \pm 0.08^{\mathrm{a}}$ \\
\hline
\end{tabular}

Data expressed as means \pm S.E.M. CI: cardiac index, MAP: mean arterial pressure, SVR: systemic vascular resistance, PVP: portal venous pressure, PTBF: portal tributary blood flow, PTVR: portal tributary vascular resistance, HCVR: hepatocollateral vascular resistance, HABF: hepatic arterial blood flow. PVL: partial-portal-vein-ligated, Sham: sham-operated. ${ }^{a} P<0.05$ vs Sham group, ${ }^{\mathrm{b}} P<0.05$ vs $P V L-$ vehicle group.

Table 2. Hemodynamic values in sham-operated rats and chronic bile-duct-ligated rats receiving vehicle or synephrine $(1 \mathrm{mg}$ $/ \mathrm{kg}$ per $12 \mathrm{~h}$ ) for 8 days

\begin{tabular}{lccc}
\hline & Sham rats & BDL- vehicle rats & BDL-synephrine rats \\
\hline Number of rats & 7 & 7 & 7 \\
CI $(\mathrm{ml} / \mathrm{min}$ per $100 \mathrm{~g})$ & $27.3 \pm 2.0$ & $48.9 \pm 2.3^{\mathrm{a}}$ & $39.7 \pm 2.0^{\mathrm{ab}}$ \\
MAP $(\mathrm{mmHg})$ & $121 \pm 4$ & $94 \pm 4^{\mathrm{a}}$ & $116 \pm 5^{\mathrm{b}}$ \\
Heart rate $(\mathrm{bpm})$ & $330 \pm 4$ & $316 \pm 13$ & $304 \pm 13$ \\
SVR $\left(\mathrm{dyn} \cdot \mathrm{s} \cdot \mathrm{cm}^{-5} \times 10^{3} / 100 \mathrm{~g}\right)$ & $368 \pm 33$ & $157 \pm 11^{\mathrm{a}}$ & $237 \pm 15^{\mathrm{ab}}$ \\
PVP $(\mathrm{mmHg})$ & $6.2 \pm 0.2$ & $16.9 \pm 0.4^{\mathrm{a}}$ & $15.2 \pm 0.4^{\mathrm{ab}}$ \\
PTBF $(\mathrm{ml} / \mathrm{min}$ per $100 \mathrm{~g})$ & $2.83 \pm 0.26$ & $4.85 \pm 0.29^{\mathrm{a}}$ & $3.86 \pm 0.35^{\mathrm{ab}}$ \\
PTVR $\left(\mathrm{dyn} \cdot \mathrm{s} \cdot \mathrm{cm}^{-5} \times 10^{3} / 100 \mathrm{~g}\right)$ & $3435 \pm 355$ & $1314 \pm 117^{\mathrm{a}}$ & $2204 \pm 264^{\mathrm{ab}}$ \\
HCVR $\left(\mathrm{dyn} \cdot \mathrm{s} \cdot \mathrm{cm}^{-5} \times 10^{3} / 100 \mathrm{~g}\right)$ & $184 \pm 18$ & $284 \pm 17^{\mathrm{a}}$ & $333 \pm 33^{\mathrm{a}}$ \\
HABF $(\mathrm{ml} / \mathrm{min} \mathrm{per} 100 \mathrm{~g})$ & $0.60 \pm 0.05$ & $1.43 \pm 0.15^{\mathrm{a}}$ & $1.31 \pm 0.21^{\mathrm{a}}$
\end{tabular}

Data expressed as means \pm S.E.M. CI: cardiac index, MAP: mean arterial pressure, SVR: systemic vascular resistance, PVP: portal venous pressure, PTBF: portal tributary blood flow, PTVR: portal tributary vascular resistance, HCVR: hepatocollateral vascular resistance, HABF: hepatic arterial blood flow. BDL: bile-duct-ligated, Sham: sham-operated. ${ }^{a} P<0.05$ vs Sham group, ${ }^{\mathrm{b}} P<0.05$ vs BDL-vehicle group.

tetrandrine (27) or tetramethylpyrazine (28) did have inadvertent side effects in terms of further reduction in systemic arterial pressure or resistance in cirrhotic or portal hypotensive animals. In contrast, synephrine administration exerted the distinct advantage of improving the systemic vasodilative state in portal hypertensive animals, even compared with propranolol $(18-20)$ or octreotide (14, 20, 21). On the other hand, the magnitude of reduction in PVP and PTBF by synephrine in PVL rats was smaller than that by propranolol (32\% and 39\%, respectively) or octreotide ( $28 \%$ and $68 \%$, respectively) (20), indicating that synephrine at $1 \mathrm{mg} / \mathrm{kg}$ per $12 \mathrm{~h}$ is not as efficacious as propranolol at $30 \mathrm{mg} / \mathrm{kg}$ per day or octreotide at $100 \mu \mathrm{g}$ $/ \mathrm{kg}$ per $12 \mathrm{~h}$. As the present study and previous studies have shown, it seems paradoxical that both the $\alpha_{1}$-adrenoceptor agonist synephrine and the $\alpha_{1}$-adrenoceptor antagonist prazosin $(2,3,23)$ can ameliorate portal hypertension and splanchnic hyperemia in portal hypertensive animals. Synephrine is a vasoconstrictor of mesenteric arteries (6) and probably exerts its portal hypotensive effects through splanchnic vasoconstriction and thereby reducing PTBF, whereas prazosin probably exerts its portal hypotensive effects through reducing intrahepatic and porto-systemic vascular resistances. According to Ohm's law, P (pressure) $=\mathrm{Q}($ flow $) \times \mathrm{R}$ (resistance) $(1,2)$, the mechanisms of portal hypotensive action by the $\alpha_{1}$-adrenoceptor agonist synephrine and the $\alpha_{1}$-adrenoceptor antagonist prazosin can be attributed to reduction of flow and resistance, respectively 
$(1,2)$. Synephrine has been administered clinically to shock patients with effective pressor effects (29). In healthy human volunteers (7) and anesthetized dogs (8), acute infusion of synephrine induced both systemic pressor and positive inotropic effects, suggesting activation of both vascular $\alpha$-adrenoceptors and myocardial $\beta$-adrenoceptors $(7-9)$. Whereas in the present study, repeated gavage administration of synephrine into portal hypertensive and cirrhotic rats resulted in predominant activation of vascular $\alpha$-adrenoceptors. It remains to be clarified whether differences in species, disease state or dose regimens contribute to discrepant results in $\beta$-adrenoceptor activation by synephrine.

In the present study, synephrine was given to PVL rats immediately after partial portal vein ligation, but given to BDL rats three weeks after bile duct ligation, as portal hypertension immediately ensues in the former procedure, while it takes at least three weeks for portal hypertension to develop in the latter procedure (16). The rationale for starting synephrine treatment immediately after portal vein stenosis was that early administration of portal hypotensive drugs achieves better results in the amelioration of the hyperdynamics and porto-systemic shunting in portal hypertensive rats $(18,24,30)$. The possibility of synephrine inhibiting liver fibrosis in BDL rats, thereby contributing to portal pressure reduction, can not be ruled out, as the design of the present study did not address this issue primarily. It is likely that in the present study, there will be a problem in keeping a stable plasma concentration of synephrine in the rats by gavage. The main advantage of gavage administration is that in comparison with parenteral administration, it is more convenient and suitable for repeated or even chronic drug administration.

In summary, eight-day administration of synephrine $(1 \mathrm{mg} / \mathrm{kg}$ per $12 \mathrm{~h})$ moderately but significantly ameliorated portal hypertension and systemic as well as splanchnic hyperemic state of PVL and BDL rats.

\section{Acknowledgments}

This study was supported in part by grants from National Health Research Institute (NHRI-GT-EX89B721C), National Science Council (NSC 89-2320-B-010-111 and NSC 89-2314-B-075-068) and Department of Health (CCMP89104-RD-110) in Taiwan.

\section{REFERENCES}

1 Groszmann RJ and de Francis R: Portal hypertension. In Schiff's Diseases of the Liver, Edited by Schiff ER, Sorrell MF and Maddrey WC. 8th ed, pp 387 - 442, Lippincott-Raven Publishers, Philadelphia (1999)

2 Lebrec D: Pharmacological treatment of portal hypertension: present and future. J Hepatol 28, 896 - 907 (1998)

3 D'Amico G, Pagliaro L and Bosch J: Pharmacological treatment of portal hypertension: an evidence-based approach. Semin
Liver Dis 19, 475 - 505 (1999)

4 Walker S: Vasoconstrictor therapy in bleeding esophageal varices. Hepato-gastroenterology 37, 538 - 543 (1990)

5 Cales P, Oberti F, Payen J-L, Naveau S, Guyader D, Blanc P, Abergel A, Bichard P, Raymond J-M, Canva-Delcambre V, Vetter D, Valla D, Beauchant M, Hadengue A, Champigneulle B, Pascal J-P, Poynard T, Lebrec D and the French-Speaking Club for the Study of Portal Hypertension: Lack of effect of propranolol in the prevention of the development of large oesophageal varices in patients with cirrhosis: a randomized trial. Eur J Gastroenterol Hepatol 11, 741 - 745 (1999)

6 Huang Y-T, Wang G-F, Chen,C-F, Chen C-C, Hong C-Y and Yang MCM: Fructus Aurantii reduced portal pressure in portal hypertensive rats. Life Sci 57, 2011 - 2020 (1995)

7 Hofstetter R, Kreuder J and von Bernuth G: Effect of oxedrine on the left ventricle and the peripheral resistance. Arzneimittelforschung 35, 1844 - 1846 (1985)

8 Chen X, Huang QX, Zhou TJ and Dai HY: Studies of Citrus aurantium and its hypertensive ingredients on the cardiac functions and hemodynamics in comparison with dopamine and dobutamine. Acta Pharm Sin 15, 71 - 77 (1980)

9 Tang W and Eisenbrand G: Citrus spp. In Chinese Drugs of Plant Origin, pp 337 - 349, Springer-Verlag, Berlin (1992)

10 Chojkier M and Groszmann RJ: Measurement of portal systemic shunting in the rat by using $\gamma$-labeled microspheres. Am J Physiol 240, G371 - G375 (1981)

11 Huang Y-T, Wang G-F, Yang MCM, Chang S-P, Lin H-C and Hong C-Y: Vascular hyporesponsiveness in aorta from portal hypertensive rats: possible sites of involvement. J Pharmacol Exp Ther 278, 535 - 541 (1996)

12 Kountouras J, Billing BH and Scheuer PJ: Prolonged bile duct obstruction: a new experimental model for cirrhosis in the rat. Br J Exp Pathol 65, 305 - 311 (1984)

13 Chang F-C, Huang Y-T, Lin H-C, Hong C-Y, Lin J-G and Chen $\mathrm{K}-\mathrm{J}$ : Beneficial effects of combined terlipressin and tetramethylpyrazine administration on portal hypertensive rats. Can J Physiol Pharmacol 77, 618 - 624 (1999)

14 Lin H-C, Yang MC-M, Hou M-C, Li S-M, Huang Y-T, Yu P-C, Tsai Y-T and Lee S-D: Effects of long-term administration of octreotide in portal vein stenosed rats. Hepatology 23, $537-543$ (1996)

15 Sikuler E, Kravetz D and Groszmann RJ: Evolution of portal hypertension and mechanisms involved in its maintenance in a rat model. Am J Physiol 248, G618 - G625 (1985)

16 Colombato LA, Robin M, Pomier-Layrargues G and Huet P-M: Animal models of portal hypertension. In Portal Hypertension, Edited by Holstege A, Hahn EG and Scholmerich J, pp 3-14, Kluwer Academic Publishers, London (1995)

17 Lee SS, Girod C, Braillon A, Hadengue A and Lebrec D: Hemodynamic characterization of chronic bile duct-ligated rats: effect of pentobarbital sodium. Am J Physiol 251, G176 - G180 (1986)

18 Lin H-C, Soubrane O, Cailmail S and Lebrec D: Early chronic administration of propranolol reduces the severity of portal hypertension and portal-systemic shunts in conscious portal vein stenosed rats. J Hepatol 13, 213 - 219 (1991)

19 Sarin SK, Groszmann RJ, Mosca PG, Rojkind M, Stadecker MJ, Bhatnager R, Reuben A and Dayal Y: Propranolol ameliorates the development of portal-systemic shunting in a chronic murine schistosomiasis model of portal hypertension. J Clin Invest 87, $1032-1036(1991)$ 
20 Huang Y-T, Cheng Y-R, Lin H-C, Hou M-C, Lee S-D and Hong $\mathrm{C}-\mathrm{Y}$ : Hemodynamic effects of eight-day octreotide and propranolol administration in portal hypertensive rats. Dig Dis Sci 43, $358-364$ (1998)

21 Albillos A, Colombato LA, Lee F-Y, Groszmann RJ: Octreotide ameliorates vasodilatation and $\mathrm{Na}^{+}$retention in portal hypertensive rats. Gastroenterology 104, $575-579$ (1993)

22 Lin H-C, Huang Y-T, Cheng Y-R, Hou M-C, Lee F-Y, Chang F-Y, Tsai Y-T and Lee S-D: Effect of long-term octreotide and isosorbide dinitrate on haemodynamics in rats with portal vein stenosis. Clin Sci 94, 645 - 650 (1998)

23 Lin H-C, Wu H-L, Huang Y-T, Hou M-C and Hong C-Y: Haemodynamic effects of eight-day octreotide and prazosin administration in portal hypertensive rats. Eur J Clin Invest 28, $622-628(1998)$

24 Lin H-C, Soubrane O and Lebrec D: Prevention of portal hypertension and portosystemic shunts by early chronic administration of clonidine in conscious portal vein-stenosed rats. Hepatology 14, 325 - 330 (1991)

25 Reichen J, Hirlinger A, Ha HR and Sagesser S: Chronic verapamil administration lowers portal pressure and improves hepatic function in rats with liver cirrhosis. J Hepatol 3, 49-58 (1986)

26 Huang Y-T, Liu,T-B, Cheng Y-R, Lin H-C, Chen C-F and Chen S-M: Chronic portal hypotensive effects of tetrandrine and verapamil on portal hypertensive rats. Asia Pac J Pharmacol 12, $31-35$ (1997)

27 Huang Y-T, Cheng Y-R, Lin H-C, Chen C-F and Hong C-Y: Haemodynamic effects of chronic tetrandrine treatment in portal hypertensive rats. J Gastroenterol Hepatol 12, 585 - 589 (1997)

28 Chang F-C, Huang Y-T, Hong C-Y, Lin J-G and Chen K-J: Haemodynamic effects of chronic tetramethylpyrazine administration on portal hypertensive rats. Eur J Gastroenterol Hepatol 11, 1027 - 1031 (1999)

29 Huang YK: Clinical observation on synephrine and $N$-methyltyramine in the treatment of 53 cases with shock. Chin J Integr Trad West Med 4, 95 - 96 (1984)

30 Lee F-Y, Colombato LA, Albillos A and Groszmann RJ: Administration of $N^{\omega}$-nitro-L-arginine ameliorates portal-systemic shunting in portal-hypertensive rats. Gastroenterology 105, $1464-1470$ (1993) 